\title{
Avaliação de técnica de tomaticultura em gramado (TEG) na amazônia oriental
}

\author{
Simon S. Cheng; Elizabeth Y. Chu; Luiz S. Poltronieri \\ Embrapa Amazônia Oriental, C. Postal 48, 66.095-100, Belém-PA. E-mail: ewing@cpatu.embrapa.br
}

\section{RESUMO}

No Brasil, o tomateiro é cultivado principalmente em época de baixa precipitação e temperaturas amenas como as regiões Sudeste, Nordeste e Centro Oeste. Na Amazônia Oriental, uma região tropical úmida de baixa altitude, com temperatura elevada, a cultura do tomateiro enfrenta muitas dificuldades. A baixa produtividade e a mortalidade das plantas têm reduzido o número de produtores desta hortaliça, com a produção local de tomate inferior a $0,1 \%$ do volume comercializado anualmente. A técnica de Tomaticultura Em Gramado (TEG) foi concebida em 1997 e aperfeiçoada em 1998, para solucionar os problemas da tomaticultura sob clima quente e chuvoso da Amazônia, usando dois principais mecanismos: 1. Campo gramado para controlar a proliferação de doenças, pragas, plantas invasoras, erosão e lixiviação de nutrientes. 2. Queima de descarte de madeira na área de cultivo para eliminar a grama e reduzir a acidez e pobreza do solo. O presente trabalho apresenta resultados preliminares de tomaticultura sob essa nova técnica, com avaliação de produtividade, ciclo da planta e peso médio do fruto. A nova técnica de cultivo permitiu a produtividade de $5,6 \pm 0,2 \mathrm{~kg}$ por planta, sendo o período de colheita de 60 a 80 dias. A TEG demonstrou ser uma alternativa promissora para o sistema de produção de tomate na região quente e chuvosa, usando a gramínea como protetora e limpadora do solo.

Palavras-chave: Lycopersicon esculentum, sistema de produção, clima tropical chuvoso, produtividade, ciclo produtivo.

\begin{abstract}
Evaluation of TEG (grassland tomato cropping technique) in Eastern Amazon, Brazil

In Brazil, tomatoes are cultivated principally in seasons with low precipitation and cool temperature such as in regions of Southeast, Northeast and Central west. In East Amazon, a humid tropical region of low altitude with high temperature, tomato cropping faces many difficulties. Low yield and plant mortality had reduced the number of tomato growers, with annual local production less than $0.1 \%$ of total volume commercialized. The grassland tomato cropping technique (TEG) was elaborated in 1997 and improved in 1998 to solve the problems of tomato production under hot and humid climate of Amazon, by using two major mechanisms: 1. Grassland or turfgrass field is used to control the proliferation of diseases, pests, weeds, erosion and leaching of the soil nutrients. 2. Burning of waste wood materials on planting sites to eliminate the graminea and to reduce the soil acidity and poverty. The present paper shows the preliminary results of the tomato cropping using this new technique with evaluation in yields, production cycle and average fruit weight. The new cropping technique allowed a yield of $5.6 \pm 0.2 \mathrm{~kg}$ of tomato per plant and 60 to 80 days of harvest duration. This technique showed to be a promising cropping system for tomato production in the hot and humid tropical region, using graminea as soil protector and soil cleaner.
\end{abstract}

Keywords: Lycopersicon esculentum, cropping system, tropical rainy climate, yield, production cycle.

(Aceito para publicação em 26 de março de 2.002)

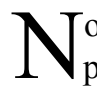
Brasil, o tomate normalmente é produzido em épocas de baixa precipitação e de temperaturas amenas nas regiões Sudeste, Nordeste e Centro Oeste. Essas regiões dispõem de estação fria e seca ou extremamente seca, contribuindo para interromper o ciclo de proliferação das doenças, pragas e plantas invasoras e reduzir tais agentes bióticas indesejáveis. Por outro lado, no trópico úmido de baixa altitude, como na Amazônia Oriental, a precipitação pluviométrica é cerca de $3.000 \mathrm{~mm} / \mathrm{ano}$, distribuída em cerca de 240 dias de chuvas de curta duração, umidade relativa do ar superior a $80 \%$ o ano todo, temperatura do ar oscilando de $22^{\circ} \mathrm{C}$ a $32^{\circ} \mathrm{C}$ diariamente no ano todo. Uma vez iniciado o cultivo, os agentes indesejáveis podem se multiplicar e permanecer no campo. Desse modo, a técnica tradicional de cultivo do tomateiro em solo descoberto não tem sustentabilidade nesta região. Segundo FAO (1994), a baixa produtividade da cultura do tomateiro (inferior a $10 \mathrm{t} / \mathrm{ha}$ ) é geral nos trópicos úmidos de baixa altitude. Na época chuvosa, no Pará, Ortiz \& Izquierdo (1994) relataram a produtividade média de 2,7 t/ha para as 14 cultivares de tomateiro introduzidas. A média por planta foi de $270 \mathrm{~g}$ apenas, devido à baixa produtividade e alta mortalidade precoce. $\mathrm{Na}$ Amazônia Oriental, a produção de tomate não chega a $0,1 \%$ do volume comercializado no mercado local, segundo Cheng (1987) e CEASA-PA (1996). A importação anual de tomate de outras regiões brasileiras é bastante significativa e da ordem de 20.000 t/ano, com valor de comercialização atacadista de R\$ 12.000.000,00.

A cobertura vegetal na superfície do solo geralmente é exigida como base de sustentabilidade nas atividades agroflorestais, porque esta prática evita erosão, lixiviação e proliferação de doenças, pragas e plantas invasoras. No campo da olericultura, a cobertura vegetal do solo é pouco estudada, embora seu efeito de sustentabilidade seja similar ao do sistema agroflorestal. Na região amazônica, o sistema de queimada de vegetação de capoeira para cultura de subsistência é o sistema mais econômico praticado pelo pequenos produtores. Embora tenha a função de adubação e de eliminação do mato, o campo perde a cobertura vegetal e se torna insustentável após dois anos de uso, atra- 
vés da perda de matéria orgânica, nutrientes químicos e invasão das plantas invasoras, doenças e pragas do solo.

A exportação de madeira é a principal atividade industrial na Amazônia Oriental, movimentando anualmente entre 300 e 500 milhões de dólares, com a produção de um milhão de metros cúbicos para exportação e a mesma quantidade de refugo. A maior parte do refugo é queimada nos pátios das indústrias madeireiras. Parte desse descarte poderia ser queimado nos campos de produção agrícola de pequena escala tais como hortas, como alternativa de uso dos recursos locais para melhorar a fertilidade do solo.

Levando em conta esses fatores, foi concebida a tomaticultura em gramado (TEG) em 1997, no Campo Experimental da Embrapa Amazônia Oriental, combinando o uso de campo gramado com a queima de descarte de madeira (somente nas áreas circulares de plantio, deixando o resto da área com cobertura de gramínea). Os tomateiros são cultivados na área com menor risco de doenças, pragas e plantas daninhas, além de melhores condições física e química do solo.

O presente trabalho foi realizado para avaliar a produtividade, peso médio e ciclo produtivo de três genótipos de tomate em 1998 e 1999, e também para determinar a potencialidade de uso desta nova técnica de produção de tomate sob o clima quente e úmido da Amazônia Oriental.

\section{MATERIAL E MÉTODOS}

A avaliação tecnológica da TEG foi realizado em campo na Embrapa Amazônia Oriental, município de Belém, durante 1998 e 1999, na época menos chuvosa, de julho a dezembro. Foram usados a cultivar de polinização aberta, C-38-D Novo (tipo Santa Cruz, multilocular, frutos de $70 \mathrm{~g}$ em média, desenvolvida em 1994 para resistência à murcha bacteriana); o híbrido experimental Pink \& Red (tipo cereja, frutos de $20 \mathrm{~g}$ em média, resistente à murcha bacteriana, resistente a rachadura sob chuvas pesadas, tipo longa vida pós-colheita) e o clone híbrido R-16-Beef (bati- zado de Pará Belo posteriormente, propagado pelo enraizamento da ponteira, frutos tipo longa vida, multilocular, frutos com até $300 \mathrm{~g}$ e resistente à murcha bacteriana). Todos genótipos foram desenvolvidos na região de Belém para adaptar às condições do Trópico Úmido Brasileiro.

Na horta gramada com capim-gengibre (Paspalum maritimo), uma gramínea nativa e agressiva da região, foi aberta uma área circular de 2,0 m de diâmetro através da queima de 50 $\mathrm{kg}$ de descarte de madeira. $\mathrm{Na}$ área queimada, dez mudas foram plantadas em covas, sendo seis no ciclo externo e quatro no ciclo interno. O cultivo seguiu as recomendações de Cheng \& Chu (2000). Cada cova recebeu $40 \mathrm{~g}$ de adubo químico, fórmula 10-28-20, e três litros de esterco de cama da granja bem curtido. As mudas foram formadas no viveiro sob cobertura de plástico agrícola e transplantadas para as covas com 25 dias de idade. Os tratos culturais no campo constaram de irrigação localizada através de tubos de PVC de $20 \mathrm{~mm}$ de diâmetro aplicada de dois em dois dias, durante 30 minutos, molhando até $30 \mathrm{~cm}$ de profundidade; tutoramento com 15 varas de 2,50 $\mathrm{m}$ de comprimento e cinco amarrios com fio de plástico para suspender os frutos e adubação semanal em cobertura de $20 \mathrm{~g}$ da formulação 10-28-20. As colheitas dos frutos maduros foram feitas duas vezes por semana, registrando o número e o peso dos frutos colhidos na área circular de $3,14 \mathrm{~m}^{2}$. Posteriormente, os dados de colheitas foram agrupados, tomando-se de período de cada cinco dias na forma acumulativa para estabelecer as curvas de produção. Da mesma maneira, foram estabelecidas as curvas de peso médio dos frutos dos três genótipos.

\section{RESULTADOS E DISCUSSÃO}

Dos resultados preliminares deste trabalho, observou-se que os fatores adversos da tomaticultura não ocorreram sob o sistema da TEG. Além disso, a adubação e a irrigação foram mantidas adequadamente, contribuindo para que os genótipos adaptados expressassem pleno potencial produtivo com safra de 60 a 85 dias (Figura 1A e Figura 1-B), contra a tradicional de 20 dias. É interessante notar que todos os três genótipos produziram em torno de $56 \mathrm{~kg}(54,51 ; 56,86$ e 58.57 $\mathrm{kg}$, respectivamente para Pink \& Red, clone R-16-Beef e C-38-D Novo) de fruto por $3,14 \mathrm{~m}^{2}$ de área circular, independente do peso médio e da quantidade de frutos produzidos, evidenciando o potencial produtivo da TEG. A produtividade média obtida foi $5,6 \mathrm{~kg}$ de frutos sadios/planta e $17,8 \mathrm{~kg} / \mathrm{m}^{2}$ de área cultivada. Este resultado pode ser considerado como um avanço tecnológico, em comparação com a média de 0,27 kg/planta (Ortiz \& Izquierdo, 1994). O híbrido Pink \& Red teve peso médio dos frutos relativamente uniforme, variando de 20 a $25 \mathrm{~g}$ (Figura 1-B), com frutos de formato globular. O clone híbrido R-16-Beef produziu frutos multiloculares com peso médio variando de 150 a $200 \mathrm{~g}$ e alguns frutos com $300 \mathrm{~g}$. O peso médio do frutos da cultivar C-38-D Novo foi de 60 a $80 \mathrm{~g}$ na primeira safra e menos que $50 \mathrm{~g}$ na segunda safra.

Foi observada diferença de comportamento na frutificação dos três genótipos estudados. O híbrido Pink \& Red e o clone R-16-Beef tiveram colheita contínua sem interrupção no período de 75 a 85 dias, enquanto a cultivar C-38-D Novo teve a colheita suspensa durante 40 dias e só retornou a florar e frutificar depois do termino da primeira safra. A segunda safra ocorreu 25 dias depois da primeira. Devido ao fim do ciclo da planta, mesmo tendo boas condições proporcionadas pelo sistema TEG, a produtividade da segunda safra foi insignificante com peso médio de fruto reduzido (Figura 1A e 1B). Para os produtores, C-38-D Novo talvez seja o genótipo mais desejado por requer menos tempo e mãode-obra para alcançar a produção máxima, enquanto, para as hortas caseiras, os genótipos que oferecem uma produção constante de tomate são mais vantajosos.

Na Amazônia Oriental, muitos fatores adversos dificultam a produção de tomate. $\mathrm{O}$ uso da TEG possibilita os 


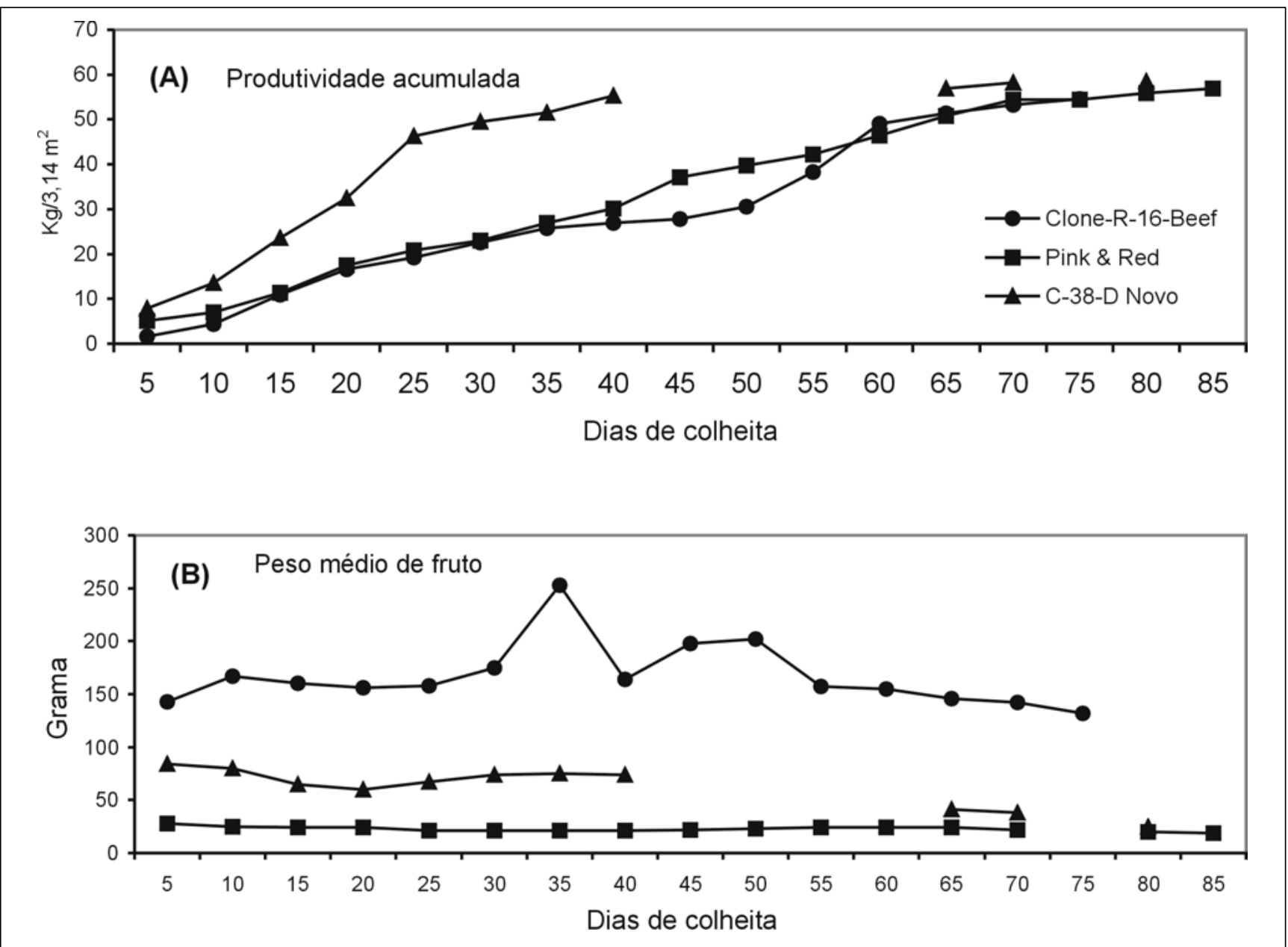

Figura 1. Produtividade acumulada, peso médio do fruto e duração de colheita de três cultivares de tomateiro (clone R-16-Beef, Pink \& Red e C-38-D Novo) plantadas sob a Técnica de Tomaticultura em Gramado (TEG), de julho a dezembro de 1998 (Pink \& Red e C-38-D Novo) e 1999 (clone R-16-Beef). Belém, Embrapa Amazônia Oriental, 1999.

produtores da região realizar o cultivo de tomate com maior segurança e sucesso. Através da TEG, a produtividade e o custo de produção são competitivos frente aos tomates importados das outras regiões brasileiras. Do modo como a TEG pode evitar os fatores indesejáveis para o cultivo do tomateiro, a técnica pode ser aplicada para outras espécies oleráceas, transformando a horta tradicional em horta gramada $(\mathrm{HG})$ para todas as regiões tropicais chuvosas. Uma horta protegida com gramado proporciona alta produtividade e boa sustentabilidade. Quando a safra terminar, o campo volta a ser ocupado pelo gramado para limpeza biológica, em vez do tradicional abandono.

Em relação à murcha bacteriana (Ralstonia solanacearum), fator limitante da produção de tomate na re- gião do trópico úmido de baixa altitude, a TEG por si só não é suficiente para evitar a ocorrência da doença, devido às condições quentes e úmidas do solo, propícias para sobrevivência da bactéria e existência de dezenas de espécies de plantas hospedeiras (Romeiro, 1996; Takasu \& Lopes, 1997). Em solo úmido com topografia plana e mal drenado, o risco de epidemia da murcha bacteriana no segundo ano de plantio no mesmo lugar é maior. Segundo Cheng \& Chu (2000), a medida mais eficaz de evitar a ocorrência desta doença é o uso de solo seco para cultivo do tomate com cuidado de higiene nas operações culturais, além de material genético resistente. Para se obter melhor resultado da TEG, o cultivo deve ser feito na encosta do local que possui topografia ondulada e bem drenada, onde o calor e o clima seco no ve- rão impedem a sobrevivência da bactéria. Muitas pastagens abandonadas nas terras degradadas na Amazônia com tais características são ideais para a produção de tomate usando a técnica de TEG.

\section{AGRADECIMENTO}

Para desenvolvimento de uma tecnologia inédita como a TEG, foi necessária a colaboração e orientação de vários colegas e mestres. Os autores gostariam de expressar os seus mais sinceros agradecimentos aos Drs. João Bosco Carvalho da Silva, José Amauri Buso, da Embrapa-Hortaliças e José Furlan Junior, da Embrapa Amazônia Oriental, pela valiosas sugestões, e ao Dr. Mark J. Bessett, da University of Florida, pelas análises do mérito da tecnologia desenvolvida. 


\section{LITERATURA CITADA}

CEASA-PA. Estatística de comercialização de produtos hortícolas. 1996.

CHENG, S.S. Vale a pena produzir hortaliças na Amazônia? Horticultura Brasileira, v. 5, n. 1, p. 4-7, maio, 1987.
CHENG, S.S.; CHU, E.Y. Tomaticultura em gramado (TEG) na região do Trópico Úmido Brasileiro. Belém: Embrapa Amazônia Oriental, 2000, 28 p. (Circular Técnica 3)

FAO - Production Year Book, Rome. 1994, 243 p. ORTIZ, R.; IZQUIERDO, J. Yield stability among tomato genotypes grown in Latin America and the Caribbean. Hortscience, v. 29, n. 10, p. 1175-1177, 1994.
ROMEIRO, R.S. Bactérias fitopatogênicas. Viçosa: Imprensa Universitária, 1996, 238 p.

TAKATSU, A; LOPES, L.A. Murcha bacteriana em hortaliças: Avanços cientificos e perspectivas de controle. Horticultura Brasileira, v. 15, suplemento, p. 170-177, 1997. 